\title{
Psychotic Symptoms and Sensory Impairment: Findings from the 2014 Adult Psychiatric Morbidity
}

Survey

Running Title: Sensory Impairment and Psychotic Symptoms

Natalie Shoham (Clinical Training Fellow, University College London), Gemma Lewis (Research Associate in Epidemiology, University College London), Joseph Hayes (National Institute of Health Research University College London Hospital Biomedical Research Centre Fellow and an Honorary Consultant in General Adult Psychiatry in Camden and Islington NHS Foundation Trust, University College London), Sally McManus (Associate, National Centre for Social Research), Reza Kiani (Consultant in Intellectual Disability Psychiatry \& Honorary Senior Lecturer, University of Leicester), Traolach Brugha (Professor of Psychiatry, University of Leicester), Paul Bebbington (Emeritus Professor of Social and Community Psychiatry, University College London), Claudia Cooper (Professor in Psychiatry of Older Age, University College London)

Corresponding Author: Natalie Shoham

Division of Psychiatry, $6^{\text {th }}$ Floor, Maple House, 149 Tottenham Court Road, London. W1T 7BN. Natalie.shoham.16@ucl.ac.uk

Abstract Word Count:

Text body word count: 


\section{Abstract}

Purpose

Psychosis is reportedly associated with hearing and visual impairment. The mechanisms for this are poorly understood. Using data from the 2014 English Adult Psychiatric Morbidity Survey, we hypothesised: that hearing and visual impairments would be associated with psychotic symptoms; that the probability of psychotic symptoms would be related to the severity of impairment; and that these associations would be partly explained by reduced social fulfilment.

\section{Methods}

We analysed cross-sectional data using logistic regression. Visual and auditory impairment comprised the exposures, while screening positive on the Psychosis Screening Questionnaire (PSQ) was the outcome. We used structural equation modelling to assess mediation by social fulfilment, measured by the Social Functioning Questionnaire.

\section{Results}

Screening positive on the PSQ was strongly associated with visual impairment overall (Adjusted Odds Ratio (AOR) 1.81, 95\% Confidence Intervals (Cl) 1.33 to 2.44 ), but especially with moderate visual impairment (AOR 2.75, 95\% $\mathrm{Cl} 1.78$ to $4.24, \mathrm{p}<0.001$ ). Psychotic symptoms were associated with a severe degree of hearing impairment (AOR 4.94, 95\% Cl 1.66 to $14.67, p=0.004$ ), but less so with hearing impairment overall (AOR $1.50,95 \% \mathrm{Cl} 1.10$ to $2.04, \mathrm{p}=0.010$ ). Social functioning accounted for approximately $50 \%$ of associations with both types of sensory impairment, though confidence intervals were broad.

\section{Conclusions}

Our findings support a relationship between psychotic symptoms and visual impairment (particularly moderate impairment), and a linear association between psychosis and hearing impairment. Social functioning may mediate these relationships and so form an adjunctive target for intervention, alongside sensory correction. These associations should be investigated longitudinally. 
Key words: Psychotic symptoms, visual impairment, hearing impairment, social fulfilment 


\section{Introduction}

In the UK, one in eight people has impaired hearing ${ }^{1}$. This increases with age, as age-related cochlea damage is the single greatest cause ${ }^{1,2}$. Hearing impairment, defined as an inability to hear sounds softer than 40 decibels, can have a major impact on social participation ${ }^{1}$. There are also nearly two million people living with sight loss in the UK, of whom around 360,000 are registered blind or partially sighted ${ }^{3}$. The World Health Organisation (WHO) defines visual impairment as a visual acuity of less than 0.3 or a visual field of below 30 degrees ${ }^{4}$.

Psychotic symptoms may be sufficient to meet diagnostic criteria for a psychotic disorder or fall below the required threshold. A 2016 systematic review found that people with hearing impairment were at greater risk of psychotic symptoms than those without hearing impairment ${ }^{5}$. One study found an age-specific association between hearing impairment and psychosis due to disruption during a critical developmental phase in early adolescence ${ }^{6}$. It has been postulated that more severe and chronic hearing impairment might carry the greatest risk of psychosis ${ }^{7,8}$. The degree to which impairment is reversible with aids might also alter its impact on psychosis ${ }^{7}$. There are case reports of new onset auditory hallucinations emerging when hearing declines ${ }^{9}$, sometimes improving or resolving when hearing aids are introduced ${ }^{10,11}$. Some studies found no association between hearing impairment and psychotic symptoms, albeit in small samples ${ }^{8,12}$. The few studies reporting reduced odds of psychosis in hearing impaired people included very small numbers of participants with psychotic disorders ${ }^{13-15}$.

A 2013 WHO survey of over 20,000 people showed that people with visual problems had increased odds of psychotic symptoms ${ }^{16}$. Both near and distance visual impairment have been implicated ${ }^{17}$. In one study, one-eighth of middle-aged, severely mentally ill patients with schizophrenia, bipolar mood disorders and major depression had distance visual impairment ${ }^{18}$. This was towards the higher end of the estimated range for the local population. 
Several competing hypotheses exist to explain the apparent association between sensory impairment and psychosis. Such impairment could be a biomarker of psychotic illness, as oxidative stress, NMDA receptor damage and deafferentation have all been noted to underlie both low-level sensory deficits and schizophrenia ${ }^{19}$. A few studies suggest an association between schizophrenia and reduced retinal fibre layer thickness ${ }^{20,21}$ and visual processing abnormalities ${ }^{22,23}$. Visual problems are also a known side effect of antipsychotic medication and might therefore be an indirect result of psychosis.

Alternatively sensory impairment might cause psychosis. Short-term sensory deprivation can induce psychotic symptoms in healthy individuals ${ }^{24} 9$. There is some early evidence implicating visual difficulties in the aetiology of psychotic symptoms. Thus a recent longitudinal study of over $1,000,000$ Swedish military conscripts showed that men with severe visual impairment had an increased risk of subsequently being diagnosed with a psychotic disorder ${ }^{25}$.

An absence of known cases of schizophrenia in congenitally cortically blind individuals has led to a proposed 'Protection against Schizophrenia' (PaSZ) model ${ }^{26}$. This suggests that the incorrect interpretation of visual information caused by partial visual impairment may increase the risk of schizophrenia; in contrast, perfect and absent vision protect against it ${ }^{26}$. This model is supported by evidence from one ${ }^{25}$, but not a second observational study ${ }^{27}$ and to our knowledge there is no other evidence to support it. In contrast there are many reported cases of psychosis occurring in profound congenital hearing impairment, so the theory that severe sensory impairment may be protective is not supported in relation to hearing ${ }^{28}$.

Another possible explanation for an association between sensory impairments and psychosis is that sensory impairment reduces opportunities for social participation, thereby increasing social isolation and loneliness, and increasing the risk of developing psychosis ${ }^{5}$. Both visual and hearing impairments may contribute to loneliness, depression and reduced social participation in older 
adults ${ }^{29-33}$, while younger adults may experience discrimination and reduced educational, social and occupational opportunities ${ }^{34}$.

These considerations led us to examine the relationship between sensory impairment and psychosis. Specifically we hypothesised that:

1. People with hearing or visual impairment would be more likely to report psychotic symptoms than people without such impairments, and this would correspond to the degree of impairment.

2. The association between sensory impairment and psychotic symptoms would be mediated by reduced social fulfilment.

This is, to our knowledge, the first study to test whether reduced social fulfilment is a mechanism linking sensory impairment to psychotic symptoms; and to assess whether the level of symptoms is associated with visual impairment in a dose-dependent manner in a nationally representative sample. 


\section{Methods}

Sample

The UK Adult Psychiatric Morbidity Survey (APMS) is a cross-sectional household survey, conducted every 7 years since $1993^{35}$. Questions on sensory impairment were included for the first time in the most recent (2014) survey. This involved interviews with 7,546 members of the general English population aged over $16^{35}$. It was a stratified, multi-stage probability sample. Participants were selected randomly from households, which themselves had been randomly selected from postal areas stratified according to socioeconomic variables. The response rate was $57 \%$. Data are weighted to account for non-response and selection probability. Permission to use the data for the current study was granted by NHS Digital.

\section{Outcome Measures}

The Psychosis Screening Questionnaire (PSQ) is a screening tool for detecting the presence of psychotic symptoms ${ }^{36}$. It had high sensitivity and specificity for identifying psychosis cases in a general practice sample ${ }^{36}$. The original PSQ included clusters of questions each relating to 6 symptoms: hypomania, thought interference, persecution, perceptual abnormalities, 'strange experiences' and hallucinosis; 20 questions in total. In APMS the hypomania cluster was excluded, leaving 5 clusters and 17 questions. Endorsing one or more clusters on the PSQ is indicative of the presence of clinically significant psychotic symptoms ${ }^{37}$. We considered individuals as experiencing psychotic symptoms if any one cluster was endorsed; this required a specific answer to more than one question.

\section{Exposure variables}

Participants were asked whether they had difficulty hearing or wore a hearing aid as a single question with a yes/no response, thus providing a binary exposure variable. We also analysed the severity of hearing impairment as a second exposure variable. Participants who responded yes to 
the first question were asked: (With your hearing aid) how would you describe your difficulty hearing? - No difficulty, mild difficulty, moderate difficulty, severe difficulty, or cannot do. We combined the severe difficulty and cannot do categories in order to increase statistical power and precision of estimates.

People were also asked how much difficulty they had reading a newspaper (near vision impairment), and seeing a face across the room (distance vision impairment), even with visual aids. They gave their answers as a degree of difficulty on a Likert scale (again no difficulty, mild difficulty, moderate difficulty, severe difficulty, or cannot do). We combined the near and distance categories of visual impairment, recording the more severe degree of visual impairment from either category. Again we combined the severe and cannot do categories, analysing the presence of any degree of visual impairment as a binary exposure variable, and the degree of visual impairment as a second exposure.

\section{Potential mediator}

Reduced social fulfilment was analysed as a potential mediator of the relationship between sensory impairment and psychotic symptoms (Figure 1). The Social Functioning Questionnaire (SFQ) is a validated eight-item scale measuring perceived social functioning on a score ranging from 0 to $24{ }^{38}$. Lower scores represent better functioning. Feelings of loneliness, stress, relationships, and enjoyment of leisure time are among the items covered. The total SFQ score was used as a proxy continuous measure of social fulfilment.

\section{Confounders}

As potential confounding variables in the models testing associations between sensory impairment and psychosis we included age (in 10 year brackets), gender, and ethnicity, together with housing tenure and highest educational qualification (as markers of socioeconomic status). Ethnicity was coded as White British, White Other; Black / African / Caribbean / Black British; Asian / Asian British, 
or mixed/multiple ethnic groups/other ethnic groups. The highest educational qualification was coded as Degree/ Teaching / Higher National Diploma / Nursing, A Level, GCSE or equivalent, Foreign/other, or No Qualifications. Tenure was coded as owned outright, buying with a mortgage or loan, paying part rent and part mortgage (shared ownership), rental, living rent free, or squatting.

We also included the Alcohol Use Disorders Identification Test (AUDIT) score ${ }^{39}$. These variables were included as potential confounders if they were differentially distributed among those exposed and unexposed and those with and without the outcome, or if they had been previously recognised to be associated with the exposure and outcome and not on the causal pathway.

\section{Sensitivity Analyses}

We did not adjust for estimated verbal IQ in our main analyses, because this would have restricted the analytic sample to native English speakers only ${ }^{40}$. We ran separate analyses adjusting for this. We did not adjust for current use of antipsychotic medication in the main analyses, as this is a result of the outcome, but we performed a separate sensitivity analysis when visual impairment was the exposure variable. We also performed a sensitivity analysis in which participants who reported screening positive on the PSQ purely due to the presence of auditory or visual hallucinations were removed from the analytic sample, in order to exclude the possibility that hallucinations resulting directly from sensory deprivation were the sole driver of the association. We also separately tested for an interaction between age (in 10 year brackets) and sensory deprivation in relation to PSQ results, in case older and younger people were affected differently by sensory impairment. Finally, we performed a sensitivity analysis in which reports of having received a diagnosis of psychosis or schizophrenia was the outcome.

\section{$\underline{\text { Statistical Analysis }}$}

We undertook complete case analyses in Stata version $15^{41}$. The weighting used in the original APMS survey was preserved in our study using the Stata svy command. Where missing data meant that a stratum contained only one primary sampling unit, the observations within that unit were moved to 
an adjacent stratum to allow the variation within each stratum to be calculated ${ }^{42}$. This was essential to preserve the weighting without loss of data. We report weighted percentages, but unweighted absolute numbers. We explored differences between those with and without missing data.

We used logistic regression to assess whether people with hearing or visual impairment (as binary exposures) had increased odds of screening positive on the PSQ relative to those without. The exposure variable was presence either of hearing impairment or of visual impairment. The outcome was whether the participant screened positive on the PSQ.

We also carried out logistic regressions with the degree of hearing or visual impairment as separate exposures and screening positive on the PSQ as the outcome. Univariable models were run initially, followed by multivariable models including relevant confounding variables.

Finally, we built structural equation models using the Stata gsem command, appropriate for binary outcomes, to test to what extent reduced social fulfilment might account for the associations between sensory impairment and screening positive on the PSQ. An estimated percentage mediation was obtained by dividing the indirect effect of the exposure on the outcome, via the mediator, by the total effect of the exposure on the outcome (including any direct effect). We used additive log coefficients in these calculations, but present their exponentials in the results section.

\section{Results}

\section{Sample Demographics}

Of 7546 people who participated in the AMPS, 7107 provided all relevant data and constitute the analytic sample. Table 1 shows the demographic characteristics of this sample according to sensory impairment. 435 (6.4\%) screened positive on the PSQ. Hearing impairment was reported by 1207 (14.3\%), while 934 (11.9\%) reported visual impairment, and 241 (2.6\%) reported both.

People with sensory impairment were more likely to be aged over 65 and widowed, and less likely to have a degree. 
Of people in the sample, $45(<0.1 \%)$ reported having been diagnosed with schizophrenia or psychosis at some time. $53.4 \%$ of this group screened positive on the PSQ, compared to $6.2 \%$ reporting no diagnosis of psychosis.

\section{$\underline{\text { Missing Data }}$}

Participants with missing data were less likely to be aged over 65 (37\% vs $20.8 \%$ ). They were slightly less likely to be Asian or Asian British (3.8\% vs 7.1\%), and more likely to be from a mixed or 'other' ethnic group ( $4.8 \%$ vs $2.5 \%$ ). They were more likely to have no qualifications ( $34.1 \%$ vs $19.7 \%$ ), and to own their home outright (41.6\% vs $31 \%$ ). A similar proportion of people excluded from the analytic sample, relative to those included, scored positive on the PSQ $(5.5 \%$ with missing data vs $6.4 \%$ without). People with missing data were more likely to report hearing impairment ( $23.1 \%$ vs $14.3 \%)$ and visual impairment (18.7\% vs $11.9 \%)$.

A further 242 people were excluded from the mediation analysis because they had not completed the SFQ.

\section{Visual Impairment and Psychosis}

We found evidence of an association between visual impairment and a positive PSQ result, even after controlling for potential confounders ((Adjusted Odds Ratio (AOR) 1.81, 95\% confidence intervals $(\mathrm{Cl}) 1.33-2.44, \mathrm{p}<0.001)$. (Table 2). When levels of impairment were analysed, we found strongest evidence that moderate visual impairment was associated with screening positive on the PSQ, including following adjustment ( $A O R 2.75,95 \% \mathrm{Cl} 1.78$ to $4.24, \mathrm{p}<0.001)$. There was weak evidence for an association with mild ( $A O R 1.49,95 \% \mathrm{Cl} 0.99$ to $2.24, \mathrm{p}=0.054$ ), but not severe visual impairment (AOR $1.43,95 \% \mathrm{Cl} 0.60$ to $3.42, \mathrm{p}=0.423$ ) (Table 3 ). The mediation analysis attributed $50 \%$ (95\% $\mathrm{Cl} 18 \%$ to $81 \%, \mathrm{P}=0.002$ ) of the association between visual impairment and psychotic experiences to reduced social fulfilment (Table 4).

\section{Hearing Impairment and Psychosis}


There was weak evidence for an association between any hearing impairment and screening positive on the PSQ following adjustment for potential confounders ( $A O R$ 1.50, 95\% $\mathrm{Cl} 1.10$ to $2.04, \mathrm{p}=0.010$ ) (Table 2). Severe hearing impairment was significantly associated with screening positive on the PSQ, although the confidence intervals were wide (AOR 4.94, 95\% $\mathrm{Cl} 1.66$ to $14.67, p=0.004$ ). We found weak evidence that mild hearing impairment was associated with a positive PSQ result (AOR 1.59, 95\% $\mathrm{Cl} 1.07$ to $2.35, \mathrm{p}=0.022$ ), but evidence for an association with moderate hearing impairment fell short of conventional levels of significance despite the odds ratio being very similar (AOR 1.56, $95 \% \mathrm{Cl} 0.92$ to $2.64, \mathrm{p}=0.097)$. Odds of psychosis were highest in severe hearing impairment (Table 3).

Mediation analysis suggested that reduced social functioning accounted for $42 \%$ of the association between any hearing impairment and PSQ result, although the 95\% confidence intervals were wide (95\% $\mathrm{Cl} 5 \%$ to $79 \%, \mathrm{p}=0.026$ ). (Table 4 )

\section{Sensitivity Analyses}

Adjustment for estimated verbal IQ slightly weakened the evidence of association between mild visual impairment and PSQ (OR 1.39, 95\% $\mathrm{Cl} 0.90$ to $2.15, \mathrm{p}=0.137)$. It weakened the evidence of an association between PSQ and mild hearing impairment (OR 1.28, 95\% $\mathrm{Cl} 0.85$ to $1.93, \mathrm{p}=0.235$ ), and hearing impairment overall (OR $1.36,95 \% \mathrm{Cl} 1.00$ to $1.87, \mathrm{p}=0.053)$. It strengthened the evidence of association between moderate hearing impairment and PSQ (OR 1.71, 95\% $\mathrm{Cl} 1.02$ to $2.88, \mathrm{p}=0.043$ ). Of note, there were no participants with an intellectual disability (estimated verbal IQ lower than 70) in the sample.

Adjusting for whether participants reported currently using antipsychotic medications did not alter the adjusted results in which vision was the exposure variable.

Excluding participants who screened positive on the PSQ solely due to reporting hallucinations did not markedly affect the associations with presence of overall visual impairment. It did however 
slightly weaken the association of severe hearing impairment with screening positive on the PSQ (AOR 4.01, 95\% $\mathrm{Cl} 1.23$ to $13.06, p=0.021$ ), and reduced the strength of association with hearing impairment overall ( $A O R=1.47,95 \% \mathrm{Cl} 1.06$ to $2.05, p=0.022$ ). It markedly weakened the association between mild visual impairment and screening positive on the PSQ (AOR 1.38, 95\% $\mathrm{Cl} 0.90$ to 2.11 , $\mathrm{p}=0.145)$.

There was no evidence of association between either hearing or visual impairment and reporting a diagnosis of schizophrenia or psychosis.

There was also no evidence of an interaction between age and sensory impairment in influencing PSQ result. 


\section{Discussion}

\section{Main Findings}

We found evidence that visual impairment was associated with screening positive on the PSQ, and moderate visual impairment was more strongly associated than a mild or severe degree. This association was driven purely by hallucinosis. Over half of the association between visual impairment and psychotic symptoms could be accounted for by poorer social fulfilment. While hearing impairment overall was weakly associated with screening positive on the PSQ, the association was stronger with greater impairment of hearing.

\section{Comparison with Existing Literature}

Our finding that hearing impairment is associated with psychosis is consistent with previous literature ${ }^{5}$. Our finding that severe hearing impairment is the most strongly associated is consistent with a straightforward, linear relationship between psychosis and hearing impairment.

The finding that visual impairment overall is associated with psychosis accords with results from three previous longitudinal studies $25,43,44$, but is at odds with a study of over 600,000 Israeli military conscripts. The latter found refractive errors to be associated with a reduced risk of later schizophrenia ${ }^{27}$. This may be because the prevalence of refractive error in that sample was lower than would usually be expected ${ }^{25}$. This was also a young sample, who may have been affected differently to the older population with sensory impairment in the APMS sample. The finding that moderate visual impairment is the most strongly associated is at odds with the concept of a doseresponse relationship, and may be explained in several ways. If visual impairment is a biomarker of psychosis, then perhaps the pathological process involved does not cause eyesight to deteriorate to a severe level. If it is a consequence of the treatment or reduced ability for self-care, then again this may be the case. Alternatively, this finding is consistent with the 'Protection against Schizophrenia' model whereby reduced or absent vision are protective against schizophrenia. Lastly, the 
participants with the most severe visual impairment reported greater median social fulfilment than those with moderate impairment; so mediation by social functioning remains plausible.

\section{Strengths and Limitations}

Strengths of this study include the large, nationally representative sample and adjustment for a broad range of potential confounders. The inclusion of people who were not in contact with clinical services widens the remit of the investigation. The use of a screening tool for psychosis also meant that we examined a broad population. Our study included females, unlike the two large studies of military conscripts described above ${ }^{25,27}$.

There are a number of limitations. Our analyses were cross-sectional, so we cannot determine temporal association between the outcome, exposure and mediator. We cannot therefore cannot draw any firm conclusions as to whether sensory impairments are a cause of psychosis, a biomarker, or even a consequence of people with psychosis having poorer general health. It is also possible that the nature of the association is bidirectional.

In addition, sensory impairment was self-reported rather than objectively assessed by ophthalmological or audiology services. This might have affected the validity of the measurement. People with psychotic symptoms may be less able to assess their own sensory capabilities accurately, for example if they perceive their vision to be worse than it is due to visual processing difficulties, or if they have less contact with other people and therefore do not realise they are less able to hear speech. The same may apply to social fulfilment.

We do not know how many participants had congenital versus acquired sensory impairment, and these have been shown to be differently associated with psychosis ${ }^{28}$. Neither did we know how many people in our study were British Sign Language (BSL) users. Using sign language early on in the family environment facilitates the development of language as well as psychosocial and emotional development in deaf children, which might protect against mental health problems ${ }^{45}$. 
Being a household survey, the APMS excludes people who have been hospitalised due to severe psychotic illness or who live in hostels, or were unable or unwilling to participate as a result of psychosis. This might have introduced a selection bias leading to an underestimation of associations between psychosis and sensory impairment. It has been estimated that people living in communal establishments make up fewer than $2 \%$ of the overall UK population, so the effect of this should have been minimal ${ }^{35}$. People with significant sensory impairment might also have been less likely to participate in the survey. As the group of APMS participants excluded from our study due to missing data had a slightly higher rate of psychosis, this might have reduced the association. However, the number of people unable to participate is likely to have been small. An unavoidable limitation of our study is the relatively small number of participants with severe sensory impairments. Consequently, some of our estimates of association lacked precision. For example, while we found an increasing odds of psychosis risk in groups with mild, moderate and severe hearing impairment, confidence intervals for these estimates overlapped.

Although we have made efforts to include all relevant confounders, residual confounding is always possible in observational studies. For example, cognitive impairment was not measured in participants aged under 60 and therefore could not be included ${ }^{46}$.

Lastly, the confidence intervals around the estimates for the percentage of the association between hearing and visual impairments and screening positive on the PSQ that was mediated by social fulfilment were very wide.

\section{Implications}

Our results suggest that visual impairment, particularly moderate impairment, is associated with psychotic symptoms. These results are more consistent the 'Protection against Schizophrenia' (PaSz) model, whereby moderate visual impairment might carry the highest risk of psychosis, than with a linear dose response relationship ${ }^{26}$. This remains inconclusive however, as we do not report data on congenitally blind individuals. More longitudinal research is needed to establish whether correcting 
refractory errors and increasing uptake of hearing aids, and otherwise reducing the incidence of sensory impairment are credible interventions for reducing the impact of psychosis. Regardless, these associations highlight the importance of assisting people with psychosis to attend opticians' and audiology appointments and address conditions that may cause sensory impairment.

Reduced social fulfilment might be one mechanism underlying a relationship between sensory impairments and psychosis: this finding requires to be tested in longitudinal studies. Social isolation and loneliness affect many people with mental illness, and may be preventable or amenable to modification through increasing social connection and support.

\section{Acknowledgements}

Supported by the University College London Hospital National Institute of Health Research Biomedical Research Centre.

Permission to use data from the 2014 Adult Psychiatric Morbidity Survey was granted by NHS Digital. 


\section{References}

1. Action on Hearing Loss. Hearing Matters Updated 2015.

2. Fortnum HM, Davis A, Summerfield AQ, Marshall DH, Davis AC, Bamford JM, Yoshinaga-Itano $C$, Hind S. Prevalence of permanent childhood hearing impairment in the United Kingdom and implications for universal neonatal hearing screening: questionnaire based ascertainment studyCommentary: Universal newborn hearing screening: implications for coordinating and developing services for deaf and hearing impaired children. $\mathrm{Bmj}$ 2001;323(7312):536.

3. NHS. Blindness and Vision Loss. Available at: https://www.nhs.uk/conditions/vision-loss/.

4. World Health Organisation. Global Initiative for the Elimination of Avoidable Blindness : action plan 2006-2011. 2007.

5. Linszen MM, Brouwer RM, Heringa SM, Sommer IE. Increased risk of psychosis in patients with hearing impairment: review and meta-analyses. Neuroscience \& Biobehavioral Reviews 2016;62:1-20.

6. van der Werf $M$, Thewissen V, Dominguez $M$, Lieb R, Wittchen $H$, van Os J. Adolescent development of psychosis as an outcome of hearing impairment: a 10-year longitudinal study. Psychological medicine 2011;41(3):477-485.

7. van der Werf $M$, van Boxtel $M$, Verhey F, Jolles J, Thewissen $V$, van Os J. Mild hearing impairment and psychotic experiences in a normal aging population. Schizophrenia research 2007;94(1-3):180-186.

8. Eastwood M, Corbin S, Reed M, Nobbs H, Kedward H. Acquired hearing loss and psychiatric illness: an estimate of prevalence and co-morbidity in a geriatric setting. The British Journal of Psychiatry 1985;147(5):552-556.

9. Bernardini F, Attademo L, Blackmon K, Devinsky O. Musical hallucinations: a brief review of functional neuroimaging findings. CNS spectrums 2017;22(5):397-403.

10. Sommer I, Roze C, Linszen M, Somers M, van Zanten G. Hearing loss; the neglected risk factor for psychosis. Schizophrenia research 2014;158(1):266-267.

11. Coebergh JA, Lauw R, Bots R, Sommer I, Blom J. Musical hallucinations: review of treatment effects. Frontiers in psychology 2015;6:814.

12. Livingston $G$, Kitchen $G$, Manela $M$, Katona $C$, Copeland J. Persecutory symptoms and perceptual disturbance in a community sample of older people: the Islington study. International journal of geriatric psychiatry 2001;16(5):462-468.

13. Moore N. Is paranoid illness associated with sensory defects in the elderly? Journal of Psychosomatic Research 1981;25(2):69-74.

14. Brodaty H, Sachdev P, Rose N, Rylands K, Prenter L. Schizophrenia with onset after age 50 years: I: Phenomenology and risk factors. The British Journal of Psychiatry 1999;175(5):410415.

15. Mason P, Rimmer M, Richman A, Garg G, Johnson J, Mottram PG. Middle-ear disease and schizophrenia: case-control study. The British Journal of Psychiatry 2008;193(3):192-196.

16. Moreno C, Nuevo R, Chatterji S, Verdes E, Arango C, Ayuso-Mateos JL. Psychotic symptoms are associated with physical health problems independently of a mental disorder diagnosis: results from the WHO World Health Survey. World Psychiatry 2013;12(3):251-257.

17. Viertiö S, Laitinen A, Perälä J, Saarni SI, Koskinen S, Lönnqvist J, Suvisaari J. Visual impairment in persons with psychotic disorder. Social psychiatry and psychiatric epidemiology 2007;42(11):902. 
18. Zheng W, Tang L-R, Correll CU, Ungvari GS, Chiu HF, Xiang Y-Q, Xiang Y-T. Frequency and correlates of distant visual impairment in patients with schizophrenia, bipolar disorder, and major depressive disorder. East Asian Archives of Psychiatry 2015;25(3):115.

19. Geiser E, Retsa C, Knebel J-F, et al. The coupling of low-level auditory dysfunction and oxidative stress in psychosis patients. Schizophrenia research 2017;190:52-59.

20. Pan J, Zhou Y, Xiang Y, Yu J. Retinal Nerve Fiber Layer Thickness Changes in Schizophrenia: A Meta-Analysis of Case-Control Studies. Psychiatry Research 2018.

21. Adams SA, Nasrallah HA. Multiple retinal anomalies in schizophrenia. Schizophrenia research 2017.

22. Császár $\mathrm{N}$, Kapócs $\mathrm{G}$, Bókkon I. A possible key role of vision in the development of schizophrenia. Reviews in the neurosciences 2018.

23. Silverstein SM, Rosen R. Schizophrenia and the eye. Schizophrenia Research: Cognition 2015;2(2):46-55.

24. Mason OJ, Brady F. The psychotomimetic effects of short-term sensory deprivation. The Journal of nervous and mental disease 2009;197(10):783-785.

25. Hayes JF, Picot S, Osborn DP, Lewis G, Dalman C, Lundin A. Visual Acuity in Late Adolescence and Future Psychosis Risk in a Cohort of 1 Million Men. Schizophrenia bulletin 2018.

26. Landgraf S, Osterheider M. "To see or not to see: that is the question." The "ProtectionAgainst-Schizophrenia"(PaSZ) model: evidence from congenital blindness and visuo-cognitive aberrations. Frontiers in psychology 2013;4:352.

27. Caspi A, Vishne T, Reichenberg A, et al. Refractive errors and schizophrenia. Schizophrenia research 2009;107(2-3):238-241.

28. Atkinson JR, Gleeson K, Cromwell J, O'Rourke S. Exploring the perceptual characteristics of voice-hallucinations in deaf people. Cognitive neuropsychiatry 2007;12(4):339-361.

29. Contrera KJ, Betz J, Deal J, et al. Association of hearing impairment and anxiety in older adults. Journal of aging and health 2017;29(1):172-184.

30. Jayakody DM, Almeida OP, Speelman CP, Bennett RJ, Moyle TC, Yiannos JM, Friedland PL. Association between speech and high-frequency hearing loss and depression, anxiety and stress in older adults. Maturitas 2018;110:86-91.

31. Han J, Lee $\mathrm{H}$, Jung J, Park E-C. Effects of self-reported hearing or vision impairment on depressive symptoms: a population-based longitudinal study. Epidemiology and psychiatric sciences 2018:1-13.

32. McManus S, Lord C. Circumstances of people with sight loss: secondary analysis of Understanding Society and the Life Opportunities Survey. Natcen report for RNIB 2012.

33. Stam M, Smit JH, Twisk JW, Lemke U, Smits C, Festen JM, Kramer SE. Change in Psychosocial Health Status Over 5 Years in Relation to Adults' Hearing Ability in Noise. Ear and hearing 2016;37(6):680-689.

34. Du Feu M, Fergusson K. Sensory impairment and mental health. Advances in psychiatric treatment 2003;9(2):95-103.

35. McManus S, Bebbington $P$, Jenkins $R$, Brugha T. Mental Health and Wellbeing in England: Adult Psychiatric Morbidity Survey 2014: a Survey Carried Out for NHS Digital by NatCen Social Research and the Department of Health Sciences, University of Leicester: NHS Digital; 2016.

36. Bebbington $\mathrm{P}$, Nayani T. The psychosis screening questionnaire. International Journal of Methods in Psychiatric Research 1995.

37. Johns LC, Cannon M, Singleton N, et al. Prevalence and correlates of self-reported psychotic symptoms in the British population. The British Journal of Psychiatry 2004;185(4):298-305.

38. Tyrer P, Nur U, Crawford M, Karlsen S, MacLean C, Rao B, Johnson T. The Social Functioning Questionnaire: a rapid and robust measure of perceived functioning. International Journal of Social Psychiatry 2005;51(3):265-275. 
39. Saunders JB, Aasland OG, Babor TF, De la Fuente JR, Grant M. Development of the alcohol use disorders identification test (AUDIT): WHO collaborative project on early detection of persons with harmful alcohol consumption-II. Addiction 1993;88(6):791-804.

40. McManus SA, Ali; Bebbington, Paul; Brugha, Traolach; Cooper, Claudia; Rai, Dheeraj; Saunders, Charlotte; Strydom, Andre; Hassiotis, Angela. Inequalities in health and service use among people with borderline intellectual impairment 2018.

41. Stata Statistical Software: Release 15. College Station, TX: StataCorp LLC [computer program]. Version; 2017.

42. McDowell A. What do I do when one of the survey estimators returns an error message, "stratum with only one PSU detected"? Available at:

https://www.stata.com/support/faqs/statistics/stratum-with-one-psu/. Accessed 8th January 2019.

43. Schubert E, Henriksson K, McNeil T. A prospective study of offspring of women with psychosis: visual dysfunction in early childhood predicts schizophrenia-spectrum disorders in adulthood. Acta Psychiatrica Scandinavica 2005;112(5):385-393.

44. Schiffman J, Maeda JA, Hayashi K, et al. Premorbid childhood ocular alignment abnormalities and adult schizophrenia-spectrum disorder. Schizophrenia research 2006;81(2-3):253-260.

45. Austen S, Crocker SR. Deafness in mind: Working psychologically with deaf people across the lifespan: Wiley; 2004.

46. Livingston $G$, Sommerlad A, Orgeta $V$, et al. Dementia prevention, intervention, and care. The Lancet 2017;390(10113):2673-2734. 
Table 1: Sociodemographics of analytic sample

\begin{tabular}{|c|c|c|c|c|}
\hline $\begin{array}{l}\text { Characteristic } \\
\mathrm{N}=7107\end{array}$ & $\begin{array}{l}\text { No hearing } \\
\text { Impairment } \\
\text { n (Weighted \%) }\end{array}$ & $\begin{array}{l}\text { Hearing } \\
\text { Impairment } \\
\text { n (Weighted \%) }\end{array}$ & $\begin{array}{l}\text { No Visual } \\
\text { Impairment } \\
\text { n (Weighted \%) }\end{array}$ & $\begin{array}{l}\text { Visual } \\
\text { Impairment } \\
\mathrm{n} \text { (Weighted \%) }\end{array}$ \\
\hline Total (and \% of total sample) & $5900(85.7 \%)$ & $1207(14.3 \%)$ & $6173(88.1 \%)$ & $934(11.9 \%)$ \\
\hline $\begin{array}{l}\text { Number scoring Positive on Psychosis } \\
\text { Screening Questionnaire (PSQ) }\end{array}$ & $368(6.4 \%)$ & $67(6.3 \%)$ & $348(5.9 \%)$ & $87(9.6 \%)$ \\
\hline Male & $2280(47.8 \%)$ & $594(55.2 \%)$ & $2509(49.1 \%)$ & $365(47.4 \%)$ \\
\hline Aged over 65 & $1330(15.9 \%)$ & $713(50.2 \%)$ & $1662(19.3 \%)$ & $378(32.0 \%)$ \\
\hline $\begin{array}{l}\text { Ethnicity } \\
\qquad \text { White British } \\
\text { Any Other Ethnic Background }\end{array}$ & $\begin{array}{r}4928(79.2 \%) \\
972(20.8 \%)\end{array}$ & $\begin{array}{r}1112(89.6 \%) \\
95(10.4 \%)\end{array}$ & $\begin{array}{r}5216(80.2 \%) \\
957(19.8 \%)\end{array}$ & $\begin{array}{l}824(84.1 \%) \\
110(15.8 \%)\end{array}$ \\
\hline $\begin{array}{l}\text { Marital Status } \\
\text { Married or cohabiting } \\
\text { Single } \\
\text { Divorced or separated } \\
\text { Widowed }\end{array}$ & $\begin{array}{r}3303(61.7 \%) \\
1355(26.3 \%) \\
761(7.6 \%) \\
481(4.4 \%) \\
\end{array}$ & $\begin{array}{r}645(65.1 \%) \\
138(12.2 \%) \\
162(9.0 \%) \\
262(13.8 \%) \\
\end{array}$ & $\begin{array}{r}3521(63.0 \%) \\
1314(24.7 \%) \\
765(7.4 \%) \\
573(5.0 \%) \\
\end{array}$ & $\begin{array}{l}427(56.4 \%) \\
179(21.3 \%) \\
158(10.8 \%) \\
170(11.6 \%)\end{array}$ \\
\hline $\begin{array}{l}\text { Highest Educational Qualification } \\
\text { Degree } \\
\text { Teaching / Higher National Diploma / } \\
\text { nursing }\end{array}$ & $\begin{array}{r}1533(26.7 \%) \\
485(7.8 \%)\end{array}$ & $\begin{array}{r}210(19.5 \%) \\
95(7.9 \%)\end{array}$ & $\begin{array}{r}1576(26.6 \%) \\
509(7.9 \%)\end{array}$ & $\begin{array}{r}167(19.1 \%) \\
71(7.3 \%)\end{array}$ \\
\hline $\begin{array}{l}\text { A levels } \\
\text { GCSE or equivalent } \\
\text { Foreign / other } \\
\text { No qualifications }\end{array}$ & $\begin{array}{r}1000(19.4 \%) \\
1457(25.8 \%) \\
180(2.6 \%) \\
1245(17.6 \%)\end{array}$ & $\begin{array}{r}153(14.5 \%) \\
227(20.2 \%) \\
71(5.6 \%) \\
451(32.5 \%) \\
\end{array}$ & $\begin{array}{r}1041(19.4 \%) \\
1466(24.9 \%) \\
211(3.0 \%) \\
1370(18.3 \%)\end{array}$ & $\begin{array}{r}112(14.0 \%) \\
218(25.8 \%) \\
40(3.5 \%) \\
326(30.3 \%)\end{array}$ \\
\hline Tenure & & & & \\
\hline $\begin{array}{l}\text { Own Outright } \\
\text { Buying with help of mortgage or loan } \\
\text { / shared ownership scheme }\end{array}$ & $\begin{array}{l}1908(27.8 \%) \\
1925(35.2 \%)\end{array}$ & $\begin{array}{l}651(49.8 \%) \\
207(22.3 \%)\end{array}$ & $\begin{array}{l}2201(30.7 \%) \\
1922(34.3 \%)\end{array}$ & $\begin{array}{l}358(32.8 \%) \\
210(26.6 \%)\end{array}$ \\
\hline $\begin{array}{l}\text { Renting } \\
\text { Living rent-free (including squatting) }\end{array}$ & $\begin{array}{r}1897(32.9 \%) \\
170(4.1 \%)\end{array}$ & $\begin{array}{r}318(25.3 \%) \\
31(2.7 \%)\end{array}$ & $\begin{array}{r}1876(31.2 \%) \\
174(3.8 \%)\end{array}$ & $\begin{array}{r}339(36.2 \%) \\
27(4.4 \%)\end{array}$ \\
\hline $\begin{array}{l}\text { Currently Taking Antipsychotic } \\
\text { Medications }\end{array}$ & $66(1.0 \%)$ & $18(1.3 \%)$ & $58(0.8 \%)$ & $26(2.3 \%)$ \\
\hline Alcohol Use Disorders (AUDIT) score* & $4.2(4.6)$ & $3.7(4.2)$ & $4.1(4.4)$ & $4.0(5.3)$ \\
\hline Verbal Intelligence Quotient (IQ)* & $103.4(15.3)$ & $102.9(16.2)$ & $103.7(15.1)$ & $100.5(17.1)$ \\
\hline $\begin{array}{l}\text { Social Functioning Questionnaire (SFQ) } \\
\text { Score* }\end{array}$ & $4.2(3.5)$ & $3.9(3.4)$ & $4.0(3.4)$ & $5.1(4.1)$ \\
\hline $\begin{array}{l}\text { Reported having ever been diagnosed } \\
\text { with psychosis or schizophrenia }\end{array}$ & $31(<0.1 \%)$ & $6(<0.1 \%)$ & $29(<0.1 \%)$ & $8(<0.1 \%)$ \\
\hline
\end{tabular}

This is the analytic sample for the primary analyses.

$\mathrm{n}=$ Number in group (unweighted)

Weighted $\%=$ percentage of group weighted 
*For these variables, the mean (standard deviation) is shown.

Table 2: Odds ratios with 95\% Confidence Intervals for Screening Positive on the Psychosis Screening Questionnaire (PSQ) according to Presence of Hearing and Visual Impairment

\begin{tabular}{|l|l|l|l|l|}
\hline $\begin{array}{l}\text { Type of Sensory } \\
\text { Impairment } \\
\mathbf{n = 7 1 0 7}\end{array}$ & $\begin{array}{l}\text { Unadjusted Odds } \\
\text { Ratio relative to } \text { no } \\
\text { difficulty } \mathbf{9 5 \%} \mathbf{~ C l})\end{array}$ & P-value & $\begin{array}{l}\text { Adjusted Odds Ratio } \\
\text { relative to no difficulty } \\
\text { (95\% Cl) }\end{array}$ & P-Value \\
\hline Hearing Impairment & $0.98(0.74$ to 1.31$)$ & 0.911 & $1.50(1.10$ to 2.04$)$ & 0.010 \\
\hline Visual Impairment & $1.68(1.26$ to 2.24$)$ & $<0.001$ & $1.81(1.33$ to 2.44$)$ & $<0.001$ \\
\hline
\end{tabular}

*Adjusted for age (in 10 year brackets), gender, ethnicity, highest educational qualification, tenure and Alcohol Use Disorders Identification Test (AUDIT) score.

$\mathrm{n}=$ Total number of participants in analysis. 
Table 3: Odds of Screening Positive on Psychosis Screening Questionnaire (PSQ) by Degree of Sensory Impairment

\begin{tabular}{|c|c|c|c|c|}
\hline $\begin{array}{l}\text { Degree of Sensory } \\
\text { Impairment }\end{array}$ & $\begin{array}{l}\text { Unadjusted Odds } \\
\text { Ratio relative to no } \\
\text { difficulty }(95 \% \mathrm{Cl})\end{array}$ & P-value & $\begin{array}{l}\text { *Adjusted Odds Ratio } \\
\text { relative to no difficulty } \\
(95 \% \mathrm{Cl})\end{array}$ & P-Value \\
\hline \multicolumn{5}{|c|}{ Hearing Impairment } \\
\hline $\begin{array}{l}\text { No Difficulty } \\
\text { (Reference } \\
\text { Category) } \\
\mathrm{N}=6116\end{array}$ & 1 & & 1 & \\
\hline $\begin{array}{l}\text { Mild Difficulty } \\
\mathrm{n}=630\end{array}$ & $1.10(0.75$ to 1.60$)$ & 0.630 & 1.59 (1.07 to 2.35$)$ & 0.022 \\
\hline $\begin{array}{l}\text { Moderate Difficulty } \\
N=310\end{array}$ & 0.94 (0.58 to 1.53$)$ & 0.800 & 1.56 (0.92 to 2.64$)$ & 0.097 \\
\hline $\begin{array}{l}\text { Severe Difficulty or } \\
\text { Cannot do } \\
N=51\end{array}$ & 2.36 (0.87 to 6.39$)$ & 0.091 & 4.94 (1.66 to 14.67$)$ & 0.004 \\
\hline \multicolumn{5}{|c|}{ Visual Impairment } \\
\hline $\begin{array}{l}\text { No Difficulty } \\
\text { (Reference } \\
\text { Category) } \\
\mathrm{N}=6173\end{array}$ & 1 & & 1 & \\
\hline $\begin{array}{l}\text { Mild Difficulty } \\
N=519\end{array}$ & 1.45 (0.97 to 2.16$)$ & 0.070 & $1.49(0.99$ to 2.24$)$ & 0.054 \\
\hline $\begin{array}{l}\text { Moderate Difficulty } \\
\mathrm{N}=274\end{array}$ & $2.45(1.62$ to 3.71$)$ & $<0.001$ & 2.75 (1.78 to 4.24$)$ & $<0.001$ \\
\hline $\begin{array}{l}\text { Severe Difficulty or } \\
\text { Cannot do } \\
N=141\end{array}$ & 1.20 (0.56 to 2.59$)$ & 0.637 & $1.43(0.60$ to 3.42$)$ & 0.423 \\
\hline
\end{tabular}

*Adjusted for age, gender, ethnicity, employment type, highest educational qualification, housing tenure and Alcohol Use Disorders Identification Test (AUDIT) score.

$\mathrm{n}=$ Total number of participants in analysis. 
Table 4: Mediation Analysis: Assessment of Mediation of Association of Visual Impairment with Odds of Screening Positive on Psychosis Screening Questionnaire (PSQ) as Binary Outcome by Social Functioning Questionnaire (SFQ) Score

\begin{tabular}{|c|c|c|c|c|}
\hline $\begin{array}{l}\text { Analytic Sample } \\
n=6865\end{array}$ & $\begin{array}{l}\text { Unadjusted Odds Ratio in } \\
\text { Visual Impairment } \\
\text { (95\% Confidence } \\
\text { Interval) }\end{array}$ & P-value & $\begin{array}{l}\text { Adjusted* Odds Ratio } \\
\text { in Visual Impairment } \\
\text { (95\% Confidence } \\
\text { Interval) }\end{array}$ & P-value \\
\hline $\begin{array}{l}\text { Total effect of Visual Impairment } \\
\text { on Odds of Positive PSQ Screen }\end{array}$ & 1.59 (1.14 to 2.22$)$ & 0.006 & $1.78(1.28$ to 2.48$)$ & 0.001 \\
\hline Indirect effect via SFQ score & 1.31 (1.21 to 1.42$)$ & $<0.001$ & 1.33 (1.24 to 1.43$)$ & $<0.001$ \\
\hline \multirow{2}{*}{$\begin{array}{l}\text { Direct effect of Visual Impairment } \\
\text { on Odds of Positive PSQ Screen }\end{array}$} & $1.22(0.86$ to 1.72$)$ & 0.261 & 1.34 (0.95 to 1.89$)$ & 0.095 \\
\hline & $\begin{array}{r}\text { Unadjusted Odds Ratio in } \\
\text { Hearing Impairment } \\
(95 \% \text { Confidence } \\
\text { Interval) }\end{array}$ & P-value & $\begin{array}{r}\text { Adjusted* Odds Ratio } \\
\text { in Hearing Impairment } \\
(95 \% \text { Confidence } \\
\text { Interval) }\end{array}$ & P-value \\
\hline $\begin{array}{l}\text { Total effect of Hearing Impairment } \\
\text { on Odds of Positive PSQ Screen }\end{array}$ & $0.99(0.72$ to 1.35$)$ & 0.937 & 1.45 (1.05 to 2.00$)$ & 0.024 \\
\hline Indirect effect via SFQ score & 0.98 (0.92 to 1.04$)$ & 0.524 & $1.17(1.10$ to 1.24$)$ & $<0.001$ \\
\hline $\begin{array}{l}\text { Direct effect of Hearing } \\
\text { Impairment on Odds of Positive } \\
\text { PSQ Screen }\end{array}$ & 1.01 (0.74 to 1.37$)$ & 0.963 & 1.24 (0.90 to 1.70$)$ & 0.186 \\
\hline
\end{tabular}

*Direct effect of sensory impairment on Psychosis Screening Questionnaire (PSQ) result adjusted for age, gender, ethnicity, highest educational qualification, housing tenure, and Alcohol Use Disorders Identification Test (AUDIT) score.

Effect of sensory impairment on SFQ result adjusted for age, gender, ethnicity, highest educational qualification, housing tenure, and Alcohol Use Disorders Identification Test (AUDIT) score.

Effect of SFQ score on PSQ result adjusted for age, gender, ethnicity, housing tenure and Alcohol Use Disorders Identification Test (AUDIT) score.

$\mathrm{n}=$ Number in analysis

Total effect $=$ Combined estimated direct effect of sensory impairment on odds of screening positive on PSQ + indirect effect mediated by SFQ score

Indirect effect = Estimated effect of sensory impairment on odds of screening positive on PSQ via effect on SFQ score

Direct effect = Estimated direct effect of sensory impairment on odds of screening positive on PSQ (not via SFQ score)

Estimated degree of mediation was obtained by dividing the indirect effect by the total effect. 
Figure 1: Mediation Model

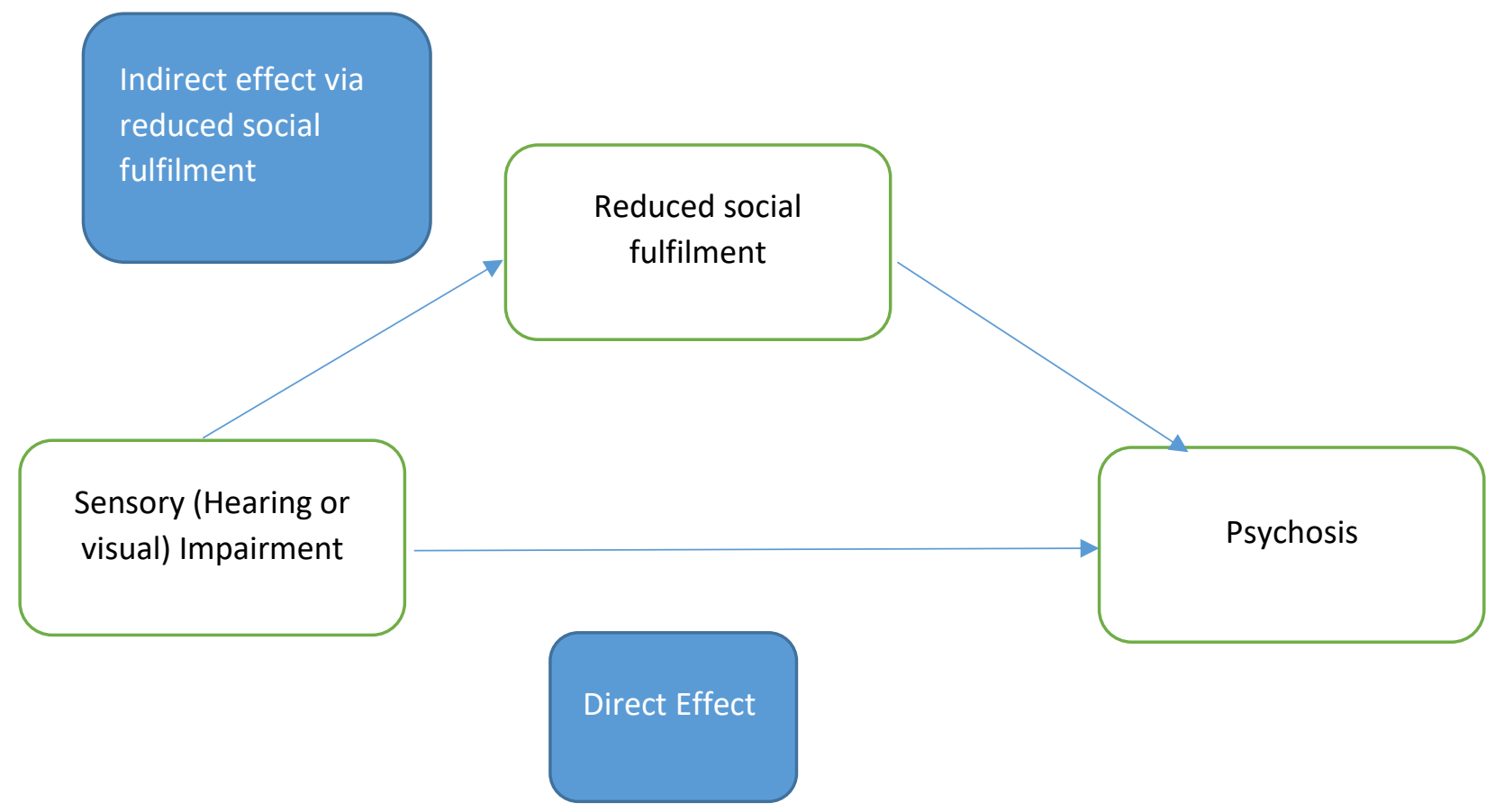

Total effect $=$ Indirect effect + direct effect 
Figure 2: Missing Data

(Could be supplementary)
7546 Adult Psychiatric Morbidity Survey participants
10 people missing data on hearing status

2 additional people missing data on visual status

82 additional people missing data on highest educational qualification

5 additional people missing data on ethnicity

317 additional people missing data on alcohol use

7107 participants remaining for primary analysis

23 additional people

missing data housing tenure

242 additional people missing Social Functioning

Questionnaire Score

6865 participants remaining for mediation analysis 